\title{
ANALISIS KEAMANAN WEBSITE OPEN JOURNAL SYSTEM MENGGUNAKAN METODE VULNERABILITY ASSESSMENT
}

\author{
Imam Riadi ${ }^{1}$, Anton Yudhana ${ }^{2}$ Yunanri.W*3 \\ ${ }^{1}$ Program Studi Sistem Informasi, Universitas Ahmad Dahlan, Indonesia \\ ${ }^{2}$ Program Studi Teknik Elektro, Universitas Ahmad Dahlan, Indonesia \\ ${ }^{3}$ Program Studi Teknik Informatika, Universitas Ahmad Dahlan, Indonesia \\ Email: ${ }^{1}$ imamriadi@is.uad.ac.id, ${ }^{2}$ eyudhana@ee.uad.ac.id ${ }^{3}$ yunanriw1607048008@webmail.uad.ac.id \\ *Penulis Korspondensi
}

(Naskah masuk: 11 April 2019 diterima untuk diterbitkan: 5 Juli 2019)

\begin{abstract}
Abstrak
Open Journal System (OJS) merupakan perangkat lunak yang berfungsi sebagai sarana publikasi ilmiah dan digunakan diseluruh dunia. OJS yang tidak dipantau beresiko diserang oleh hacker. Kerentanan yang di timbulkan oleh hacker akan berakibat buruk terhadap performa dari sebuah OJS. Permasalahan yang dihadapi pada sistem OJS meliputi network, port discover, proses audit exploit sistem OJS. Proses audit sistem pada OJS mencakup SQL Injection, melewati firewall pembobolan password. Parameter input yang digunakan adalah IP address dan port open access. Metode yang digunakan adalah vulnerability assessment. Yang terdiri dari beberapa tahapan seperti information gathering atau footprinting, scanning vulnerability, reporting. Kegiatan ini bertujuan untuk mengidentifikasi celah keamanan pada website open journal system (OJS). Penelitian ini menggunakan open web application security project (OWASP). Pengujian yang telah dilakukan berhasil mengidentifikasi 70 kerentanan high, 1929 medium, 4050 low pada OJS, Total nilai vulnerability pada OJS yang di uji coba sebesar 6049. Hasil pengujian yang dilakukan menunjukkan bahwa pada OJS versi 2.4.7 memiliki banyak celah kerentanan atau vulnerability, tidak di rekomendasi untuk digunakan. Gunakanlah versi terbaru yang dikeluarkan oleh pihak OJS Public knowledge project (PKP).
\end{abstract}

Kata kunci: OJS, Security, Vulnerability Assessment, OWASP.

\section{SECURITY ANALYSIS OPEN JOURNAL SYSTEM WEBSITE USING VULNERABILITY ASSESSMENT METHOD}

\begin{abstract}
The Open Journal System (OJS) is A software that functions as a means of scientific publication and is used throughout the world. OJS that is not monitored is at risk of being attacked by hackers. Vulnerabilities caused by hackers will adversely affect the performance of an OJS. The problems faced by the OJS system include the network, port discover, OJS system audit exploit process. The system audit process on the OJS includes $S Q L$ Injection, bypassing the firewall breaking passwords. The input parameters used are the IP address and open access port. The method used is a vulnerability assessment. Which consists of several stages such as information gathering or footprinting, scanning vulnerability, reporting. This activity aims to identify security holes on the open journal system (OJS) website. This study uses an open web application security project (OWASP). Tests that have been carried out successfully identified 70 vulnerabilities high, 1929 medium, 4050 low in OJS, the total value of vulnerability in OJS which was tested was 6049. The results of tests conducted showed that in OJS version 2.4 .7 had many vulnerabilities or vulnerabilities, not on recommendations for use. Use the latest version issued by the OJS Public Knowledge Project (PKP).
\end{abstract}

Keywords: OJS, Security, Vulnerability Assessment, OWASP.

\section{PENDAHULUAN}

Open Journal System (OJS) merupakan perangkat lunak atau software yang bersifat terbuka atau open-source (Manalu dkk, 2017). OJS bertujuan sebagai sarana publikasi karya ilmiah. OJS merupakan salah satu aplikasi web yang cukup banyak digunakan. Penggunaan OJS dari tahun 1990 sampai tahun 2018 mengalami peningkatan penggunaan semakin tinggi. Seperti pada Gambar 1 .

Penggunaan OJS yang semakin banyak, tidak menutup kemungkinan akan adanya serangan hacker yang dapat megganggu, mulai dari kurangnya 
performa OJS error akses, bahkan dapat diambil alih oleh hacker. Keamanan, menjadi solusi pada sistem OJS. Keamanan sistem OJS diperlukan untuk melindungi informasi yang terdapat didalamnya. Keamanan yang dimaksud mengacu pada kerahasiaan data, integritas dan ketersediaan layanan pada sistem yang diterapkan.

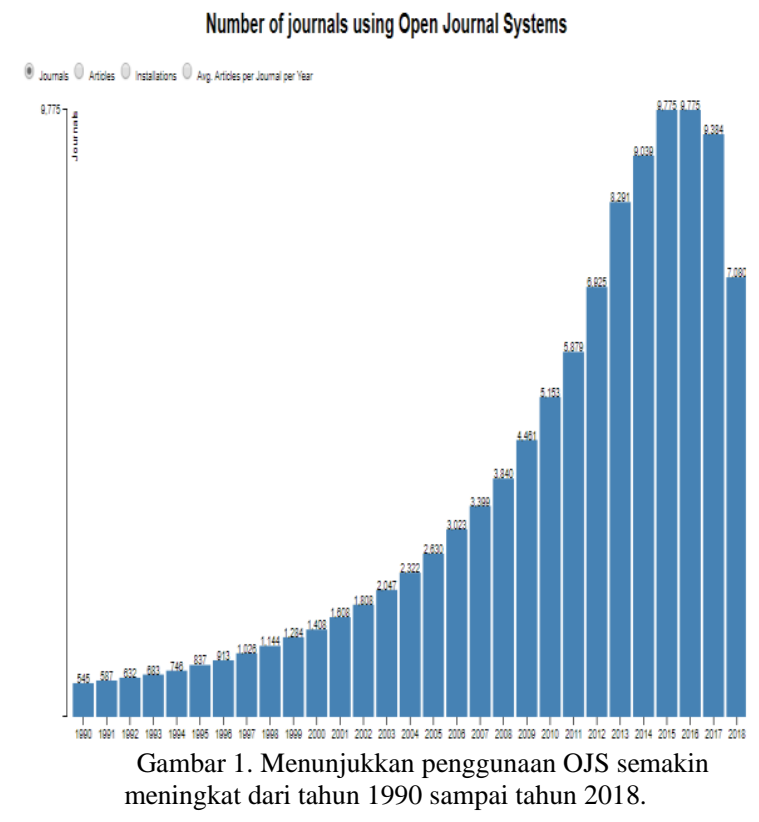

Sebuah Karya yang diterbitkan pada Open Access dapat dilihat, dibaca dan digunakan oleh semua orang yang tertarik, sehingga memungkinkan penelitian akademik memiliki dampak yang lebih besar pada dunia. Kemudahan akses pada sistem Jurnal ada di platform yang menjanjikan diseluruh dunia (Akhoon dkk, 2018).

Adanya aset data penting berupa informasi sebuah organisasi yang perlu dilindungi dengan mengikuti pendekatan yang komprehensif dan terstruktur terhadap risiko organisasi yang mungkin dihadapi. Masalah keamanan dibutuhkan penerapan metode yang dapat menjamin keamanan data, transaksi, dan komunikasi. Tidak adanya keamanan pada sistem akan berdampak buruk. Hacker dengan mudah dapat mengambil alih sistem yang dibangun. Hal ini menimbulkan permasalahan pada data yang bersifat pribadi, maupun data yang sangat penting sebuah perusahaan atau lembaga yang seharusnya tidak diketahui oleh orang lain, akan tetapi dapat di akses oleh hecker. Hacker merupakan seseorang yang memiliki kemampuan tinggi dibidang teknologi informasi.

Perlunya mengambil langkah cepat untuk mengamankan OJS dan jika diabaikan maka website OJS yang dimiliki oleh suatu badan institusi baik milik perintah, swasta, maupun perseorangan dapat mengalami kerugian yang diakibatkan oleh para hacker.
Dalam studi kasus keamanan, OJS bertujuan untuk mencari celah keamanan atau vulnerability, untuk segara diperbaiki. Kerentanan atau vulnerability pada aplikasi OJS dapat mengganggu performa OJS, bahkan dapat di ambil alih oleh hacker(Mutemwa dkk, 2018). Contoh OJS yang ditampilkan pada Gambar 2.

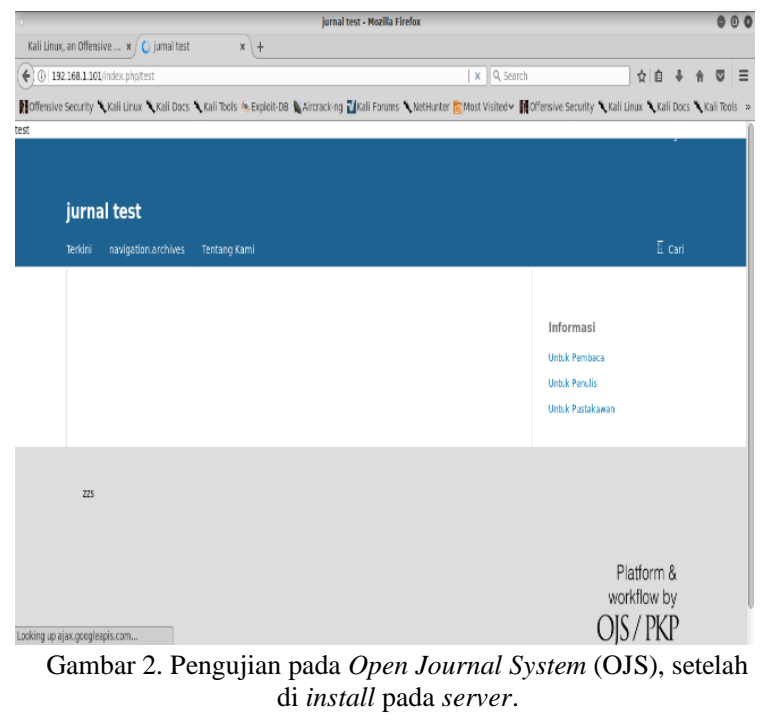

Tool yang digunakan dalam melakukan audit sistem OJS menggunakan Open Web Application Security Project (OWASP). Tool yang digunakan memiliki kemampuan untuk mendeteksi beberapa celah kerentanan antara lain :

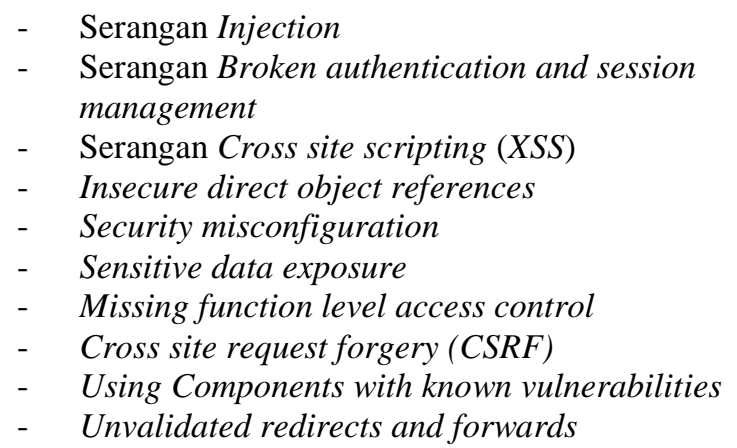

\section{METODE PENELITIAN}

Objek penelitian ini mencari vulnerability atau Celah kerentanan pada file sistem, webserver open journal system (OJS). Objek penelitian ini adalah OJS mencakup celah keamanan atau vulnerability pada sistem OJS yang berjalan pada website yang di kelola oleh admin, baik organisasi, bada atau lembaga pendidikan yang telah tersertivikasi oleh dunia (Bo Wang dkk, 2018).

Metode yang digunakan pada penelitian ini adalah metode penetration testing yang berfokus pada vulnerability assessment (Gorbenko dkk, 2017). BlackBox adalah merupakan jenis pengujian sistem tanpa mengetahui struktur rancang bangun pada sebuah sistem. Pengujian dilakukan pada open 
journal system (OJS) dan informasi mengenai jaringan maupun informasi lainnya harus di cari sendiri oleh penguji, cara ini merupakan cara yang menghasbiskan banyak waktu serta biaya yang besar(Kuniawan dkk, 2018).

Adapun sekenario pengujian dan analisis

sistem OJS adalah sebagai berikut:

a. Skenario penyerangan mengacu pada framework yang powerful seperti OWASP tool. Ditemukan nya vulnerability, pada list pada target yang di perbaiki agar mudah untuk diperbaiki dari hasil exploitasi oleh tool OWASP (Yunanri dkk, 2018).

b. Penyerangan pada page admin dan password tidak akan dirubah pada saat penetration guide dalam mencari Error code (Letian dkk, 2014).

c. Listing direktori class java mengarah pada memperoleh kode aplikasi yang mengandung kerentanan atau celah pada sistem OJS.

d. Konfigurasi stack trace ke user bertujuan mencari celah yang memiliki potensial cacat pada application OJS.

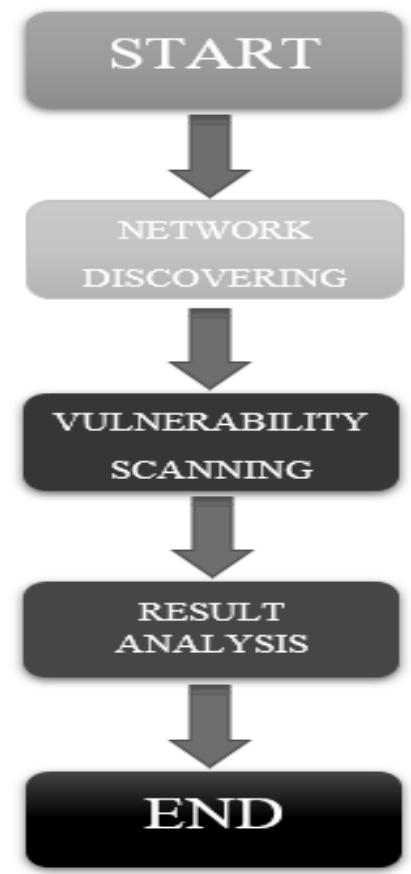

Gambar 3. Flowchart Alur Pengujian Sistem Vulnerability Assessment pada OJS

Berdasarkan Gambar 3. langkah awal pengujian penelitian perlu dilakukan pengumpulan informasi. Mengenai posisi fisik server, jenis jaringan yang digunakan, perangkat yang digunakan dan berbagai informasi yang berkaitan dengan Webserver OJS yang bisa didapatkan dengan aplikasi antara lain:

Network discover bertujuan mendapatkan informasi memindai pada port-port host yang terbuka.
- Vulnerability scanning bertujuan mencari celah kerentanan atau vulnerability pada website, server dan lain-lain.

- Result analysis merupakan kesimpulan akhir, berupa tabel dari jumlah nilai dari sebuah penelitian yang telah dilakukan.

Kemudian dilakukan pemindaian celah keamanan atau vulnerability. Yang ada pada sistem dengan menggunakan aplikasi OWASP(Ghanem dkk, 2013).

\subsection{Sistem Analisis}

Analisis sistem dilakukan untuk memperoleh informasi dari sistem yang bertujuan untuk melakukan analisis kelemahan sistem. Tahapantahapan yang dilakukan dalam mengumpulkan informasi adalah dengan menggunakan modul CEH (Elizabeth dan Jimenez, 2016). Beberapa alat yang diimplementasikan, yaitu :

a. Footprinting and Network Discover.

Fase ini adalah menemukan struktur rancang bangun dari keamanan jaringan pada target sasaran yang dituju sebagai barometer metodologi:

Whois adalah suatu prosedur untuk mendapatkan informasi mengenai sebuah domain, alamat, No.telpon, alamat email, kapan domain ini di daftarkan dan kapan domain ini akan kadarluarsa.

Nslookup adalah tool berguna untuk mengetahui IP dari sebuah domain. Disamping itu juga dapat berguna untuk mendiagnosa permasalahan jaringan yang berkaitan dengan DNS.

Scanning port adalah sebuah prosedur aplikasi yang dirancang untuk menyelidiki server atau host port terbuka. Aplikasi sering digunakan oleh administrator untuk memverifikasi keamanan jaringan.

HttpRecon adalah sebuah prosedur untuk mengumpulkan informasi pada network, webserver, yang bersifat hypertext transfer protokol.

b. Scanning Vulnerability:

Tujuan scanning vulnerability adalah mencari celah akamanan yang terdapat pada target mencapkup beberapa seperti SQL Injection, Cross Site Scripting (XSS), Remote OS Command, Path Transversal, Private IP Disclosure. pada suatu sistem operasi atau aplikasi (Kurniawan dkk, 2017).

\section{c. Reporting :}

Merupakan laporan dari awal langkah sampai akhir berbentuk file document sebagai rekomendasi langkah-langkah pencegahan perbaikan pada sistem baik perusahaan, lembaga pendidikan dan organisasi(Riadi. I dan Umar. R, 2016). 


\section{HASIL DAN ANALISIS}

Simulasi kasus dilakukan kegiatan percobaan melakukan Audit OJS pada server OJS yang dibangun sendiri menggunakan tool OWASP.

Kegiatan yang dilakukan antara lain melakukan audit berupa requsting pada server yang sudah terintergrasi open jurnal system (Barghutihi dkk, 2018). Seperti pada Gambar 4.

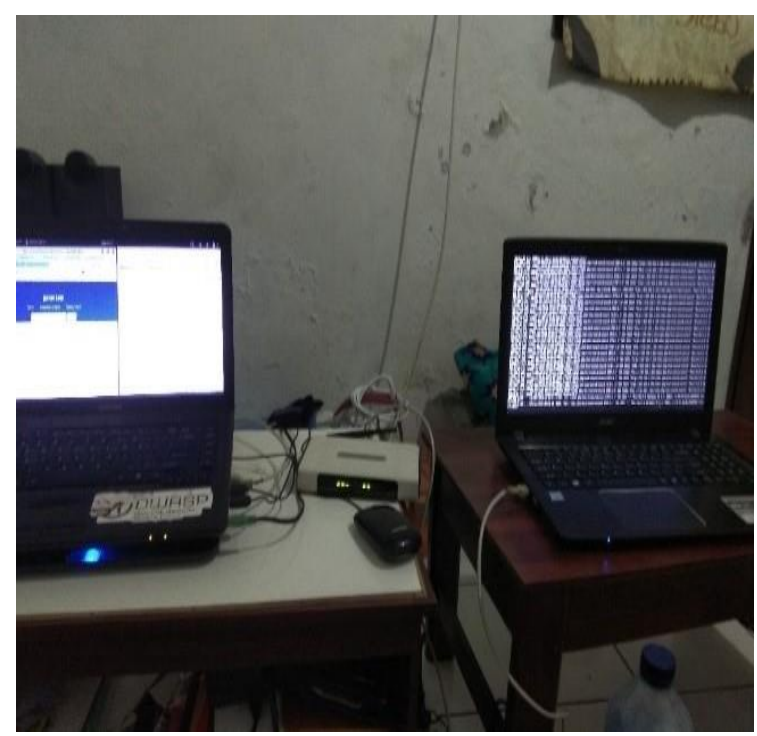

Gambar 4. Simulasi Audit Open Journal System (OJS) pada Server.

\subsection{Footprinting atau Information Gathering.}

- Whois

Merupakan suatu prosedur untuk mendapatkan informasi mengenai sebuah domain, alamat, No.telpon, alamat email, kapan domain ini di daftarkan dan kapan domain ini akan kadarluarsa.

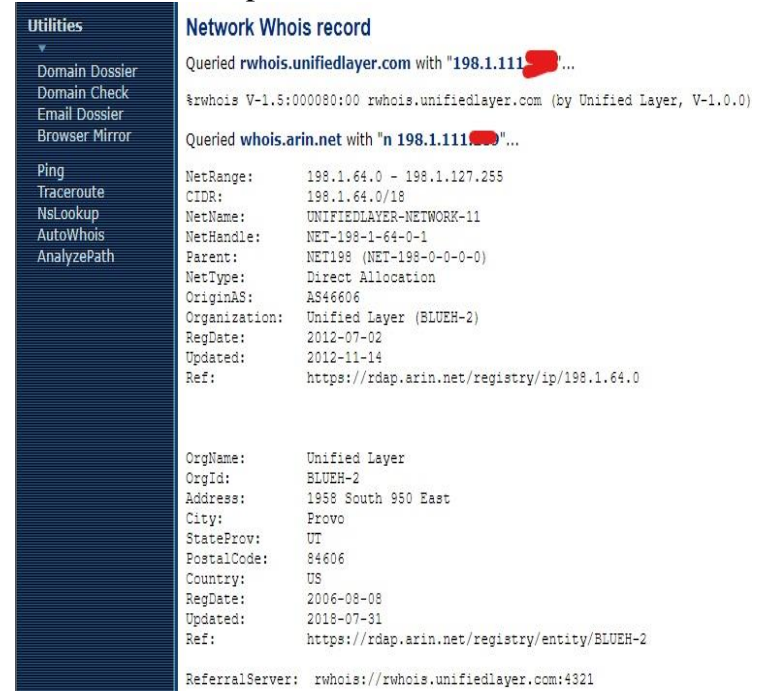

Gambar 5. Simulasi Audit Open Journal System pada Server OJS.

Gambar 5. Merupakan hasil scanning dari tool Central OPS secara real-time, pada OJS versi 2.4.7. Hasil scanning oleh tool Central OPS menampilkan informasi (Naik dan Jenkins, 2018).

- Nslookup.

Nslookup bertujuan untuk mengetahui IP dari sebuah domain. Disamping itu juga dapat berguna untuk mendiagnosa permasalahan jaringan yang berkaitan dengan DNS.

\section{Address lookup \\ canonical name insightknowledge.org. \\ aliases \\ addresses 198.1.111}

Gambar 6. Menampilkan alamat Website dan IP Address Open Journal System pada Server OJS.

Gambar 6. merupakan hasil scanning dari tool Central OPS secara real-time, pada OJS versi 2.4.7. hasil scanning oleh tool Central OPS menampilkan informasi berupa "IP Address".

\section{- Scanning Port Discover}

Merupakan sebuah prosedur aplikasi yang dirancang untuk menyelidiki server atau host port terbuka. Aplikasi sering digunakan oleh administrator untuk memverifikasi keamanan jaringan.

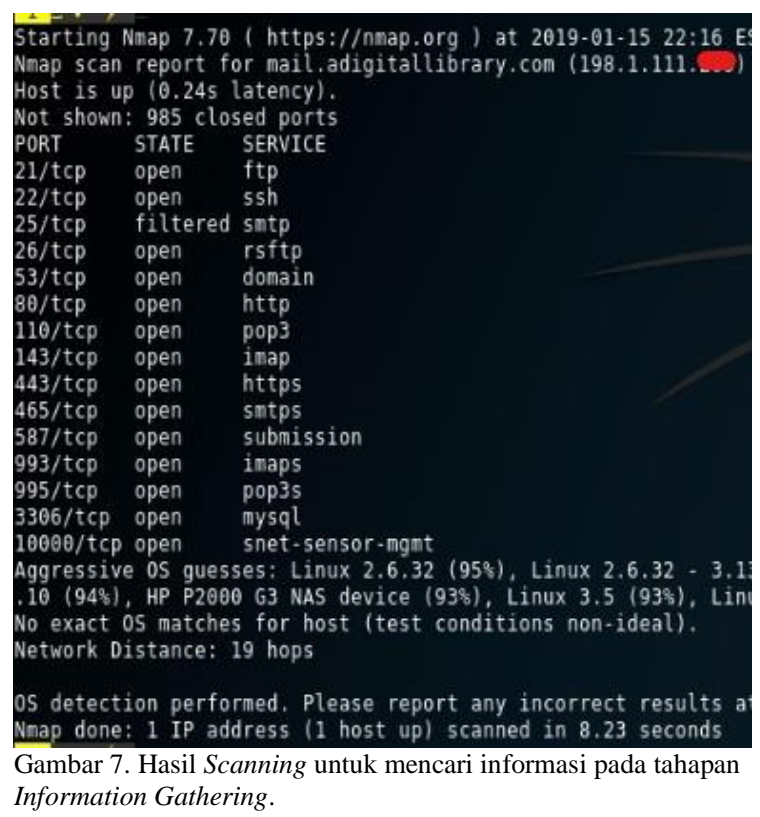

Gambar 7. Mendeteksi beberapa port yang terbuka akan sangat berbahaya, karena dengan adanya celah ini hacker dengan mudah akan masuk (Kurniawan, Riadi.I, 2018) (Yudhana dkk, 2018).

\section{- HttpRecon}

Sebuah prosedur untuk mengumpulkan informasi pada network, webserver, yang bersifat hypertext transfer protokol. 


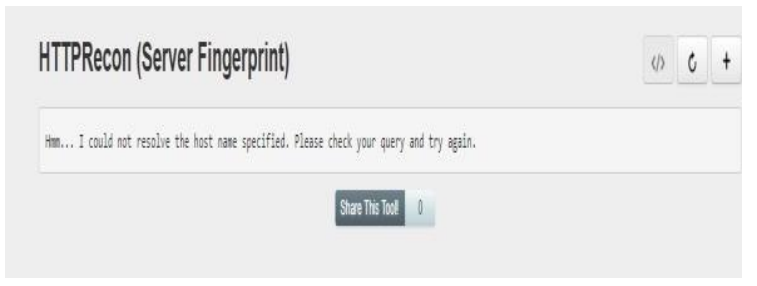

Gambar 8. Hasil Scanning untuk mencari informasi pada tahapan Information Gathering.

Gambar 8. Hasil scanning oleh tool Http Recon berupa website yang dapat melakukan audit secara otomatis yang berupa website Pada OJS versi 2.4.7. Hasil scanning Http Recon menampilkan informasi berupa " noktifikasi place chek your Query and tray again" yang menjelaskan adanya kesalahan pada query pada file sistem OJS sub Querynya (Firdausy $\mathrm{dkk}, 2008)$.

\subsection{Scanning Vulnerability (Memindai Celah keamanan).}

Vulnerability scanning bertujuan mencari celah kerentanan atau vulnerability pada website, server dan lain-lain.

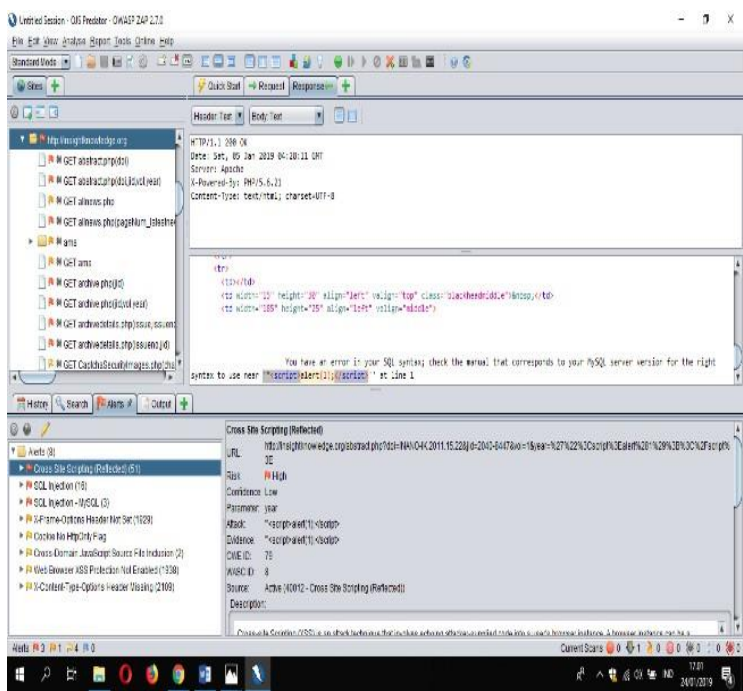

Gambar 9. Hasil scanning oleh OWASP, diperoleh 8 (sepuluh) sub file sistem yang terindikasi memiliki vulnerability.

3 (tiga) alert tersebut menampilkan adanya 3 bagian celah kerentanan atau vulnerability (Han dkk, 2018)(Mutemwa dkk, 2018)(Un, dkk, 2018), diantranya : 70 high risk, 1929 medium risk, 4049 low risk, menghasilkan alert di antaranya:

- Cross Site Scripting.

- SQ1 Injection,

- SQL Intjection MySQL.

- X-frame-Options Header Not Set.

- Cookie No. HttpOnly flag.

- Cross Domain Javascript Source file Inclusion.

- Web Browser XSS Protection not Enabled.

- X-content-type-options header missing.

Seperti yang ditampilkan pada Gambar 9.

\subsection{Hasil Analisis atau Result Analysis}

Tabel 1. Pengujian yang telah dilakukan pada Open Journal System (OJS) mendeteksi 8 sub file vulnerability, high, medium, low.

\begin{tabular}{|c|c|c|c|c|c|}
\hline \multirow{2}{*}{$\begin{array}{l}\mathrm{N} \\
\mathrm{o}\end{array}$} & \multirow{2}{*}{ Alert } & \multicolumn{3}{|c|}{ Risk } & \multirow{2}{*}{ Ket. } \\
\hline & & High & Medium & Low & \\
\hline 1 & $\begin{array}{l}\text { Cross Site } \\
\text { Scripting }\end{array}$ & 51 & & & $\begin{array}{l}\text { Hasil dari Audit } \\
\text { ini menunjukkan } \\
\text { bahwa } 3 \text { file sub } \\
\text { system perlu } \\
\text { penanganan } \\
\text { sesegera }\end{array}$ \\
\hline 2 & $\begin{array}{l}\text { SQL } \\
\text { Injection }\end{array}$ & 16 & & & $\begin{array}{l}\text { mungkin, pada } \\
\text { sub file sistem }\end{array}$ \\
\hline 3 & $\begin{array}{l}\text { SQL } \\
\text { Injection - } \\
\text { My SQL }\end{array}$ & 3 & & & $\begin{array}{l}\text { yang memiliki } \\
\text { High Risk } \\
\text { Berjumlah } 70 \text { file }\end{array}$ \\
\hline 4 & $\begin{array}{l}\text { X-Frame- } \\
\text { Options } \\
\text { Header not } \\
\text { Set }\end{array}$ & & 1929 & & $\begin{array}{l}\text { Untuk Medium } \\
\text { Risk pada OJS ini } \\
\text { tahap } \\
\text { mengkhawaturkan } \\
\text { harus segera } \\
\text { untuk diperbaikan } \\
\text { oleh admin, } \\
\text { pengelola OJS. } \\
\text { Berjumlah } 1929\end{array}$ \\
\hline 5 & $\begin{array}{l}\text { Cookie No. } \\
\text { Http Only } \\
\text { Flag }\end{array}$ & & & 1 & \\
\hline 6 & $\begin{array}{l}\text { Cross } \\
\text { Domain } \\
\text { Java Script } \\
\text { Source fikle } \\
\text { Inclusion }\end{array}$ & & & 2 & $\begin{array}{l}\text { Sementara pada } \\
\text { Posisis Low Risk }\end{array}$ \\
\hline 7 & $\begin{array}{l}\text { Web } \\
\text { Browser } \\
\text { XSS } \\
\text { Peotection } \\
\text { not Enable }\end{array}$ & & & 1938 & $\begin{array}{c}\text { masih berada } \\
\text { pada keadaan } \\
\text { kerusakan ringan, } \\
\text { Berjumlah } 4050\end{array}$ \\
\hline 8 & $\begin{array}{l}\text { X-Content- } \\
\text { Type } \\
\text { Options } \\
\text { Header } \\
\text { Missing } \\
\text { Total } \\
\text { Vulnerabilit } \\
\text { y }\end{array}$ & & 6049 & 2109 & \\
\hline
\end{tabular}

Sumber: hasil scanning mendeteksi 8 vulnerability secara keseluruhan pada OJS, menggunakan tool OWASP.

\subsection{Rekomendasi untuk perbaikan sistem OJS atau Countermeasure.}

Tabel 2. Countermeasure merupakan sebuah saran yang direkomendasi oleh tool OWASP yang memliki standar dan kualitas tinggi pada bidang IT Security (Han et al, 2018) Rekomendasi unttuk ditindaklanjuti seperti pada tabel dibawah ini:

Tabel 2. Rancangan Analisis Komputasi

\begin{tabular}{|c|c|c|c|}
\hline No. & $\begin{array}{l}\text { Nama Sub file } \\
\text { sistem } \\
\text { vulenerability }\end{array}$ & $\begin{array}{l}\text { Jumlah } \\
\text { vulnera } \\
\text { bility }\end{array}$ & $\begin{array}{l}\text { Rekomendasi } \\
\text { perbaikan ( } \\
\text { Countermeasure) }\end{array}$ \\
\hline \multirow[t]{11}{*}{1.} & \multirow{11}{*}{$\begin{array}{l}\text { Cross Site } \\
\text { Scripting (XSS) }\end{array}$} & \multirow[t]{11}{*}{51} & Tinjauan kode \\
\hline & & & sumber halaman \\
\hline & & & $\begin{array}{l}\text { kesalahan kustom, } \\
\text { pertimbangkan untuk } \\
\text { menerapkan }\end{array}$ \\
\hline & & & mekanisme \\
\hline & & & memberikan refrensi \\
\hline & & & atau pengenalan \\
\hline & & & kesalahan yang \\
\hline & & & memiliki unsur yang \\
\hline & & & unik pada klien \\
\hline & & & (browser) \\
\hline & & & server dan tidak \\
\hline
\end{tabular}


858 Jurnal Teknologi Informasi dan Ilmu Komputer (JTIIK), Vol. 7, No. 4, Agustus 2020, hlm. 853-860

\begin{tabular}{|c|c|c|c|}
\hline No. & $\begin{array}{l}\text { Nama Sub file } \\
\text { sistem } \\
\text { vulenerability }\end{array}$ & $\begin{array}{l}\text { Jumlah } \\
\text { vulnera } \\
\text { bility }\end{array}$ & $\begin{array}{l}\text { Rekomendasi } \\
\text { perbaikan ( } \\
\text { Countermeasure) }\end{array}$ \\
\hline & & & $\begin{array}{l}\text { untuk dipaparkan } \\
\text { (A.Kurniawandkk, } \\
\text { 2017). }\end{array}$ \\
\hline 2. & SQL Injection & 16 & 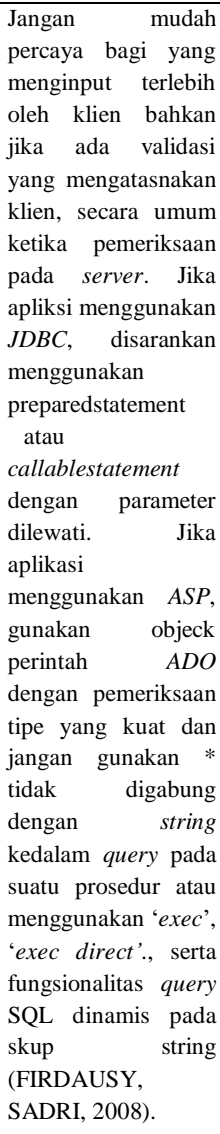 \\
\hline 3. & $\begin{array}{l}\text { SQL Injection- } \\
\text { MySQL Injection }\end{array}$ & 3 & 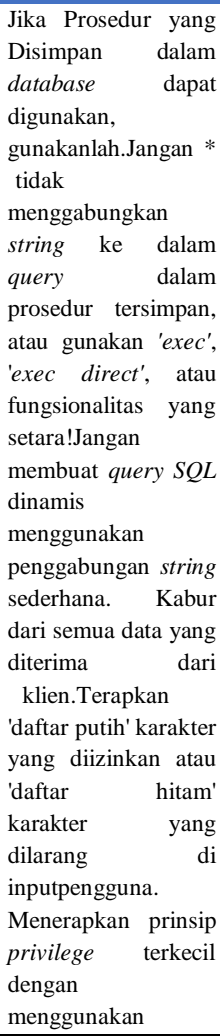 \\
\hline
\end{tabular}

\begin{tabular}{|c|c|c|c|}
\hline No. & $\begin{array}{l}\text { Nama Sub file } \\
\text { sistem } \\
\text { vulenerability }\end{array}$ & $\begin{array}{l}\text { Jumlah } \\
\text { vulnera } \\
\text { bility }\end{array}$ & $\begin{array}{l}\text { Rekomendasi } \\
\text { perbaikan ( } \\
\text { Countermeasure) }\end{array}$ \\
\hline & & & $\begin{array}{l}\text { pengguna basis data } \\
\text { yang paling } \\
\text { privilege. Secara } \\
\text { khusus, hindari } \\
\text { menggunakan } \\
\text { pengguna basis data } \\
\text { 'a' atau 'db-owner'. } \\
\text { tidak menghilangkan } \\
\text { injeksi SQL, tetapi } \\
\text { meminimalkan } \\
\text { dampaknya. Berikan } \\
\text { akses basis data } \\
\text { minimum yang } \\
\text { diperlukan untuk } \\
\text { aplikasi } \\
\text { Kurniawan 2018) }\end{array}$ \\
\hline 4. & $\begin{array}{l}\text { X-Frame -Options } \\
\text { Header not set }\end{array}$ & 1929 & $\begin{array}{lr}\begin{array}{l}\text { Pastikan } \\
\text { browser }\end{array} & \text { XSS } \\
\text { diaktifkan, } & \text { dengan } \\
\text { mengatur } & \text { header } \\
\text { respons } & \text { X-XSS }- \\
\text { Protection } & \text { HTTP ke } \\
\quad \text { '1'. }\end{array}$ \\
\hline 5. & $\begin{array}{l}\text { Cookie No. } \\
\text { HttpOnly Flag }\end{array}$ & 1 & $\begin{array}{l}\text { Pastikan bahwa } \\
\text { aplikasi / server web } \\
\text { menyetel header } \\
\text { Content-Type secara } \\
\text { tepat, dan itu } \\
\text { menetapkan header } \\
\text { X-Content-Type- } \\
\text { Options ke 'nosniff' } \\
\text { untuk semua } \\
\text { halaman web.Jika } \\
\text { memungkinkan, } \\
\text { pastikan bahwa } \\
\text { pengguna akhir } \\
\text { menggunakan } \\
\text { browser web } \\
\text { standar-compliant. }\end{array}$ \\
\hline 6 & $\begin{array}{l}\text { Cross -Domain } \\
\text { JavaScript Source } \\
\text { file inclusion }\end{array}$ & 2 & Refrensi OWASP. \\
\hline 7 & $\begin{array}{l}\text { Web browser XSS } \\
\text { Protection No. } \\
\text { enable }\end{array}$ & 1938 & Refrensi OWASP. \\
\hline 8 & $\begin{array}{l}X \text {-Content type } \\
\text { Options header } \\
\text { missing }\end{array}$ & 2109 & Refrensi OWASP. \\
\hline Total & & 6049 & \\
\hline
\end{tabular}

Sumber: Real-time oleh Open web aplication security project (OWASP).

\section{Kesimpulan}

Kesimpulan dari penelitian ini audit, diawali dengan langkah footprinting, scanning vulnerability, Reporting analysis. Kelebihan dari tool OWASP dapat melihat source code yang di tandai khusus oleh tool OWASP. Sistem metodologi yang digunakan vulnerability assessment pada penelitian ini pengujian yang dilakukan tanpa mengetahui 
struktur rancang bangun pada target yang dituju. tool OWASP berhasil menguji kerentanan sistem OJS. Pengujian yang telah dilakukan berhasil mengidentifikasi 3 tingkat kerentanan, yaitu high, medium dan low. Tingkat kerentanan diperoleh dari noktifikasi alert yang ditampilkan oleh tool OWASP. Hasil pengujian pada OJS diperoleh tool OWASP kerentanan high 70, kerentanan medium 1929 dan 4050 kerentanan low. Total celah atau vulnerability yang ditemukan berjumlah 6049. Hasil pengujian yang dilakukan menunjukkan bahwa pada OJS versi 2.4 .7 memiliki banyak celah atau kerentanan tidak di rekomendasi untuk di gunakan, gunakanlah versi terbaru yang dikeluarkan oleh pihak OJS Public knowledge project (PKP).

\section{DAFTAR PUSTAKA}

BARGHUTHI, SALEH,
ALHAMMADI, 2017. Information
Technology Trends (ITT). IEEE.
"Evaluation of Portable Penetration
Testing on Smart Cities Applications Using
Raspberry Pi III." (Itt): 25-26. higher
Colleges of Technology Sharjah, United
Arab Emirates. GHANEM dan BELATON, 2013. IEEE.Conference, Ieee International, Computer Sciences, and Universiti Sains. "Improving Accuracy of Applications Fingerprinting on Local Networks Using NMAP-AMAP-ETTERCAP as a Hybrid Framework.": 403-7. Sechool of Computer Sciences. Universiti Sains Malaysia (USM). Penang. Malaysia.

ELIZABETH dan JIMENEZ, 2016. ITCA-FEPADE. "Pentesting on Web Applications Using Ethical Hacking." (503). El Salvador.

FIRDAUSY, KARTIKA, SAMADRI, dan YUDHANA. A, 2008. TELKOMNIKA "Sistem Informasi Perpustakaan Berbasis Web Dengan Php Dan Mysql." TELKOMNIKA (Telecommunication Computing Electronics and Control) 6(2): 109. Program Studi Teknik Elektro. Universitas Ahmad Dahlan Yogyakarta. Indonesia.

AKHOON, GANAIE, dan KHAZIR, 2018. IEEE. "Research Data Management in Open Access Journals by Developed Countries." 2018 5th International Symposium on Emerging Trends and Technologies in Libraries and Information Services (ETTLIS): 116-20. Department of Lib and Information Science, University of Kashmir.

HAN WU, GAO, ZU, 2018. IEEE “An Assessment Approach of the Power System Vulnerability Considering the Uncertainties of Wind Power Integration." 2018 China
International Conference on Electricity Distribution (CICED) (201804270000656): 741-45. Student Member IEEE.

LETIAN, JIANMING, JING dan GOJUN, 2014. IEEE. "PVDF: An Automatic Patch-Based Vulnerability Description and Fuzzing Method". School of Computer, Wuhan University, China, Key Lab of Aerospace Information Security and Trusted Computing, Ministry Education, Wuhan University, China

KURNIAWAN, RIADI. I dan LUTHFI, 2017. Internasional Journal of Computer Science and Information Security (IJCSIS). "Forensic Analysis and Prevent of Cross Site Scripting in Single Victim Attack Using Open Web Application Security Project (OWASP) Framework." Journal of Theoretical and Applied Information Technology 95(6): 1363-71. Department of Informatics Engineering, Department of Information System, Department of Informatics Engineering. Islamic Univesity of Indonesia, Ahmad Dahlan University Yogyakarta, Indonnesia.

KURNIAWAN. RIADI. I, 2018. IJCSIS. “Security Level Analysis of Academic Information System Based on Standart ISO27002: 2013 Using SSE-CMM." (January). Department of Informatics Engineering Islamic Univesity of Indonesia Yogyakarta, Indonesia, Department of Information System. Ahmad Dahlan University Yogyakarta, Indonesia.

MANALU, WILLY, dan PRIATNA, 2017. IEEE. Internasional Conference on Eletrical Engineering/Electronics, Computer, Telecommunications and Information Technology (ECTI-CON). "Development of Review Rating and Reporting in Open Journal System.": 842-45. School of Computer Science, Bina Nusantara University Jakarta, Indonesia.

MUTEMWA, MTSWENI, ZIMBA, 2018. "Integrating a Security Operations Centre with an Organization' s Existing Procedures, Policies and Information Technology Systems.” 2018 International Conference on Intelligent and Innovative Computing Applications (ICONIC): 1-6. Department of Peace, Safety and Security The Council of Scientic and Industrial Resarch Pretoria, South Africa.

NAIK, dan JENKIN, 2018. "Discovering Hackers by Stealth: Predicting Fingerprinting Attacks on Honeypot Systems.” 2018 IEEE International Systems Engineering Symposium (ISSE): 1-8. Defence school of 
Comunications and Information System Ministry of Defence, United Kingdom.

RIADI. I dan UMAR. R, 2016. PPs UMY. “Analisis Forensik Serangan SQL INJECTION Menggunakan Metode Statis Forensik.": 102-3. Sistem Informasi, Teknik Informatika, Magister Teknik Infrotmatika. Universitas Ahmad Dahlan Yogyakarta, Indonesia

GORBENKO, ROMANOVSKY, TARASYUK, BILOBORODOY, $2017 . \quad$ IEEE. "Experience Report: Study of Vulnerabilities of Enterprise Operating Systems. "School of Computing, Creative Technologies \& Engineering, Leeds Backeet University, Leeds, United Kingdom (UK).

UN, MENG, GAO, BO HU, 2018. IEEE. “Universal Framework for Vulnerability Assessment of Power Grid Based on Complex Networks. ": 136-41. School of Information Science and Engineering, Northeastern University, Shenyang. State Grid Huludao Electric Power Supplay Company, Huludao.

BO WANG, dan XUNTING WANG. 2018. IEEE. "Vulnerability Assessment Method for Cyber Physical Power System Considering Node Heterogeneity." 2018 IEEE Innovative Smart Grid Technologies - Asia (ISGT Asia): 1109-13. Department of Electrical Engineering, Wuhan University, Wuhan China.

YUDHANA. A., RIADI. I., RIDHO. F, 2018. IJACSA Internasional Journal of Advanced Computer Science and Applications. "DDoS Classification Using Neural Network and Naïve Bayes Methods for Network Forensics." 9(11): 177-83. Department of Electrical Engineering, Department of Information System, and Department of Informatics Engineering. Universitas Ahmad Dahlan Yogyakarta, Indonesia. Vol 9. No.11.

YUNANRI, RIADI. I, YUDHANA. A, 2018. JURTI "Analisis Deteksi Vulnerability Pada Webserver Open Journal System Menggunakan OWASP Scanner." Magister Teknik Informatika, Sistem Informasi, Teknik Elektro. Universitas Ahmad Dahlan Yogyakarta, Indonesia. Vol 2, Juni 2018. 